\title{
Evaluation of healthcare science student learning styles based VARK analysis technique
}

\author{
Izdihar Kamal', Muhammad Khalis Abdul Karim², Mohd Mustafa Awang Kechik ${ }^{3}$, Xinni Ni", \\ Hairil Rashmizal Abdul Razak ${ }^{5}$ \\ ${ }^{1,2,3}$ Department of Physics, Faculty of Science, Universiti Putra Malaysia, Selangor, Malaysia \\ ${ }^{1,4}$ Department of Medical Imaging, School of Health Sciences, KPJ Healthcare University College, N. Sembilan, \\ Malaysia \\ ${ }^{5}$ Center for Diagnostic Nuclear Imaging, Faculty of Medicine, Universiti Putra Malaysia, Selangor, Malaysia
}

\begin{tabular}{|c|c|}
\hline Article Info & ABSTRACT \\
\hline Article history: & This study aimed to evaluate the learning styles among healthcare students \\
\hline Received May 5, 2020 & $\begin{array}{l}\text { and to study the relationship with their academic achievement. This cross- } \\
\text { sectional study was conducted among } 137 \text { healthcare students from six }\end{array}$ \\
\hline Revised Dec 26, 2020 & different courses. Data was collected using a self-administered questionnaire \\
\hline Accepted Jan 22, 2021 & $\begin{array}{l}\text { and developed based on the original visual, aural/auditory, read/write, and } \\
\text { kinesthetic (VARK) assessment. The questionnaire was divided into two }\end{array}$ \\
\hline Keywords: & $\begin{array}{l}\text { sections: the demographic status and the learning style perspective. A total of } \\
119 \text { respondents }(86.8 \%) \text { has chosen unimodal as their learning styles, while }\end{array}$ \\
\hline Healthcare student & the rest of the 18 respondents $(13.2 \%)$ choose multimodal as their preferred \\
\hline Learning style & learning method. Among the unimodal learning styles, visual $(32 \%)$ and \\
\hline Multimodal & kinesthetic methods of learning were less and accounted for $10 \%$ to $20 \%$. \\
\hline Unimodal & Notably, in multimodal learning styles preferences, $4 \%$ of students prefer a \\
\hline VARK & $\begin{array}{l}\text { combination learning style of visual and kinesthetic methods. There was no } \\
\text { significant relationship between learning styles and academic achievement } \\
\text { using Pearson's Chi-square test ( }>0.05 \text { ). Hence, both were independent of } \\
\text { one another. Hence, some of the dominant learning styles needed to be } \\
\text { considered based on their future profession. }\end{array}$ \\
\hline
\end{tabular}

This is an open access article under the $\underline{C C B Y-S A}$ license.

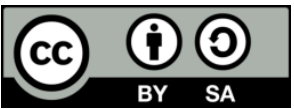

\section{Corresponding Author:}

Izdihar Kamal

Department of Medical Imaging

School of Health Sciences

KPJ Healthcare University

College 71800 Nilai, N. Sembilan, Malaysia

Email: izdihar.kamal@kpjuc.edu.my

\section{INTRODUCTION}

Learning styles can be different from each student, and basically, four common learning styles can be found among the students, namely visual (V), auditory (A), reading/write (R), and kinesthetic $(\mathrm{K})[1,2]$. For example, visual learners prefer to understand the information in pictures, maps, or diagrams. Auditory learners learn best through listening. Read/write learner preference emphasizes information show as words. Moreover, for kinaesthetic learners prefer to learn through "hand-on" and practice. Depending on the students learning styles can be categorized into unimodal and multimodal learners. Unimodal is a learner who has a strong preference in a single mode of learning, while multimodal learners learn through two or more learning styles. 
Nowadays, students are more interested in healthcare subjects, which led to an increase in healthcare courses offer in most colleges, both private and government. Most of this institution is accredited and produce an upholding the highest professionalism in healthcare education. Therefore, it is necessary to ensure that the institutions are producing a competent future healthcare worker who prepared for the services. Notably, the process of learning during the classes plays the central role for students to be good learners and success in the field. The method of students applied in the study might affect the student's academic performance [3]. Other than this, the teaching technique and the mode lecturers used to deliver knowledge to the students can influence the learning interest of students.

In most cases, the students did not realize his or her learning styles [4]. The students might not be identifying which learning method is suitable for them. The learning styles may vary based on the individual. It might be changeable or will adapt based on the environmental factors they faced or located. Healthcare students might need various methods to learn since the students need to undergo writing tests and clinical assessments before graduate and step into the real world of working. Several studies were previously done on learning styles in other countries, and the outcome of the results were varied $[2,3,5,6]$. Based on the study done by Neha, et al., many researchers agree that the learning style can have an impact on the academic performance of students [5].

In general psychology, the term learning styles refers to learners preferred general approach to learning, which includes the process of absorbing, processing, and retaining new information. The "learning styles" are aimed at the process of learning of individuals. There are various models in explaining the learning style. For example, Kolb introduced the VARK questionnaire to test the learning preferences [7]. According to Fleming, as a teacher, one's best option is to use a variety of teaching techniques to give all students the best chance to succeed. Furthermore, most people possess a dominant or preferred learning style; however, some people have a mixed and evenly balanced blend of the four types, which is visual, auditory, and kinaesthetic [8].

Learning styles are defined as the preferences way of an individual to receive and process the information given. The preferences learning styles vary among the students as to how the students gain new knowledge during the class, and most of them do not realize their learning style. The main problem that has been stated was the mode of the learning styles where the students prefer most, and students will get bored if they did not rule out their preferred learning styles. Moreover, many lecturers did not put attention and neglect on the students learning styles. Our institution, KPJ Healthcare University College (KPJUC), therefore, always wanted to provide a good study atmosphere that would understand the students need. KPJUC mainly offers six undergraduate courses in the health sciences, including a bachelor of medical imaging (BMI), a bachelor of physiotherapy (BPT), a bachelor of pharmacy (BPH), bachelor of occupational therapy (BOCT), bachelor of pharmaceutical (BPS) and bachelor of nursing (BON). All classes in health sciences include face-to-face teaching and learning through the classroom, lectures, tutorials, practical courses, seminars, and clinical connection to the real world. Therefore, this study aimed to evaluate the dominant learning style of healthcare students and to relate with the academic performance based on the type of healthcare courses.

\section{RESEARCH METHOD}

In this study, the research ethics committee of our institution had approved the research protocol for the prospective analysis with an approval ID: KPJUC/RIC/BMI/EC/2017/78. This cross-sectional study was conducted among 191 students. The survey was conducted in the KPJUC student lounge by approaching them using a non-probability convenience sampling technique. All participants agreed to the terms and signed the consent form before receives the questionnaire. Of 191, only 137 participants (from six different courses namely, bachelor of medical imaging (BMI), bachelor of physiotherapy (BPH), bachelor of pharmacy (BPH), bachelor of occupational therapy (BOT), bachelor of pharmaceutical (BPT) and bachelor of nursing $(\mathrm{BON})$ have completed the questionnaire. For those who late and incomplete, the answer has been excluded from data collection.

\subsection{Instrument}

Data was collected using a self-administered questionnaire and developed and references based on the VARK learning styles questionnaire (version 7.0) and learning styles assessment. The questionnaire was validated by psychologist and divided into two sections, namely demographic status, and learning style perspective. The first section consists of seven questions that characterize the respondents. The questions included demographic data such as ages, gender, ethnicity, year of study, courses of the respondents, achieved cumulative grade points average (CGPA), and inquire the respondents it is their first time answering the learning styles assessment questionnaire. The second section consists of 10 multiple-choice questions 
inquiring the respondents ' preferred learning styles. The four choices are related to the visual, auditory, read/ write, and finally kinaesthetic mode. Each question consists of four (A, B, C or D) selection, and the respondents allow to choose more than one option as long as their selection represented within the scenario. The questionnaire was distributed in both English and Bahasa Malaysia. After validating the questionnaire, the reliability test was conducted on the questionnaire through $10 \%$ from the sample, where 20 subjects involved in the reliability test with the test result score was 0.86 .

\subsection{Statistical analysis}

Data were analyzed using IBM SPSS version 22.0 (IBM Corporation, Armonk, New York, USA). Scores of learning styles were summed and expressed as mean and standard deviations. All the variables input was presented in descriptive analysis. The Kolmogorov-Smirnov test was used to determine the normality of the data. Differences between the two groups were determined using the Mann-Whitney U Test $(\mathrm{p}<0.05)$, while the Kruskal-Wallis $\mathrm{H}$ Test was used for more than two groups $(\mathrm{p}<0.05)$. The mean comparisons between variables were presented descriptively. Pearson correlation analysis was used to determine the association between learning style and subject's CGPA grade.

\section{RESULTS}

\subsection{Subject's demography}

The respondents were characterized by gender and course groups, as presented in Table 1. Out of 137 respondents, $83 \%$ were female, while $17 \%$ were male with their mean age $21.4 \pm 1.5$ (range $18-26$ y/o). The highest number of respondents in this study came from group course BPT and BMI which represent $50 \%$ of all subjects as shown in Figure 1. Most of the respondents were from the age group of 21 to 23 years old $(53 \%)$ and the second highest is the age from 24 to 26 years old $(23 \%)$. There were 93 respondents $(68 \%)$ were from Malay ethnicity followed by 32 respondents from India ethnicity, $(25 \%)$ and lastly 12 respondents with $(9 \%)$ of the respondents from Chinese ethnicity. Notably, there were $70 \%$ of respondents answered the learning styles assessment for the first time. On top of that, $61 \%$ of respondents are categorized in low academic achievers as the CGPA is lower than 3.5, and 39\% of respondents scored higher in CGPA more than 3.5.

Table 1. Summary of demographic among the respondents

\begin{tabular}{|c|c|c|}
\hline \multicolumn{2}{|c|}{ Socio-demographic } & $\mathrm{n}(\%)$ \\
\hline \multirow{3}{*}{ Gender } & Male & $23(17)$ \\
\hline & Female & $114(83)$ \\
\hline & 18 to 20 & $30(21.9)$ \\
\hline \multirow{4}{*}{ Age } & 21 to 23 & $71(53.3)$ \\
\hline & 24 to 26 & $31(22.6)$ \\
\hline & $>26$ & $3(2.2)$ \\
\hline & Malay & $93(67.9)$ \\
\hline \multirow[t]{2}{*}{ Ethnicity } & Chinese & $12(8.8)$ \\
\hline & India & $32(23.4)$ \\
\hline First time answering & Yes & $96(70.1)$ \\
\hline learning styles assessment & No & $41(29.9)$ \\
\hline
\end{tabular}

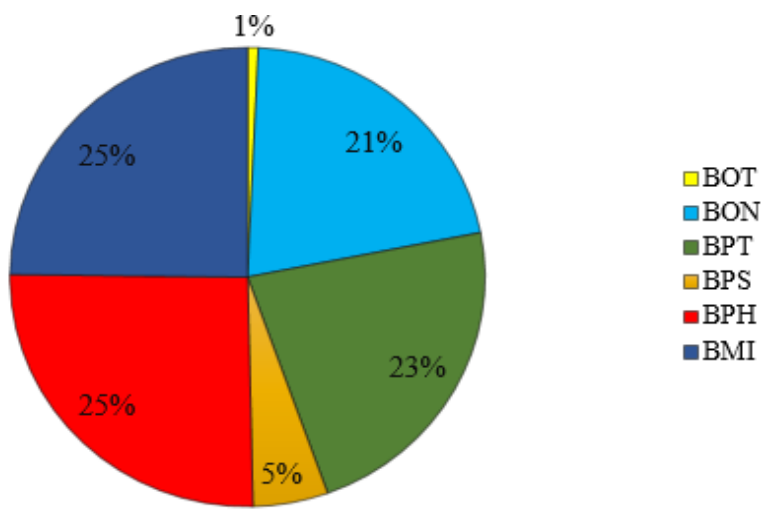

Figure 1. Percentage different of respondents based on their study course 


\subsection{Learning style assessment}

A total of 119 respondents $(86.8 \%)$ has chosen unimodal as their learning styles, while the rest of the 18 respondents $(13.2 \%)$ choose multimodal as their preferred learning method. Among the unimodal learning styles, visual $(32 \%)$ and reading $(26 \%)$ were most preferred among students. The auditory and kinesthetic methods of learning were less and accounted for $10 \%$ to $20 \%$. Notably, in multimodal learning styles preferences, the most preferred method was bimodal $14(78 \%)$, followed by trimodal $3(17 \%)$ and quadrimodal $1(5 \%)$ (Figure 2). Among $18(13.2 \%)$ of students prefer a combination learning style, $14(78 \%)$ bimodal mixed up of VK, VR, RK, AK, and AR. VK was the most preferred mode among bimodal $6(33 \%)$ as shown in Figure 3. Visual learning styles receive the highest score for both males and females. The second highest percentage prefer learning styles for males was kinesthetic, but contrary to females, the other preferred learning style was reading/writing. Table 2 shows the percentage of the score for the preferred learning style.

Table 2. Number of respondents and percentage score in each learning styles

\begin{tabular}{cc}
\hline VARK analysis & $\mathrm{n}(\%)$ \\
\hline Visual & $44(32.1)$ \\
Auditory & $13(9.5)$ \\
Reading/writing & $35(25.5)$ \\
Kinesthetic & $27(19.7)$ \\
Multimodal (VK, VR, RK, AK, and AR) & $18(13.1)$ \\
\hline
\end{tabular}

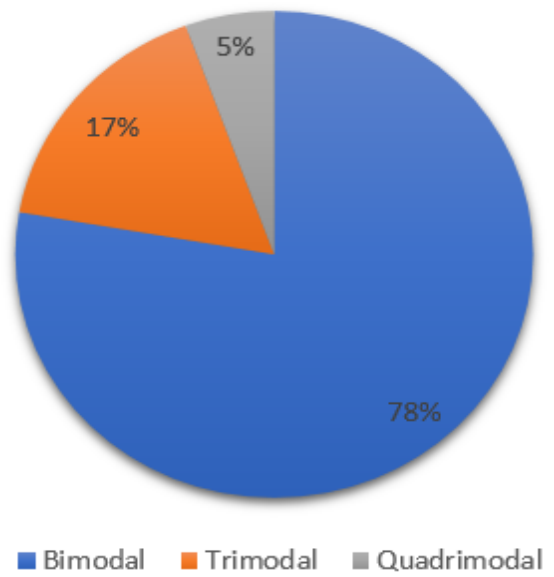

Figure 2. Percentage different of respondents who preferred multimodal learning style $(\mathrm{n}=18)$

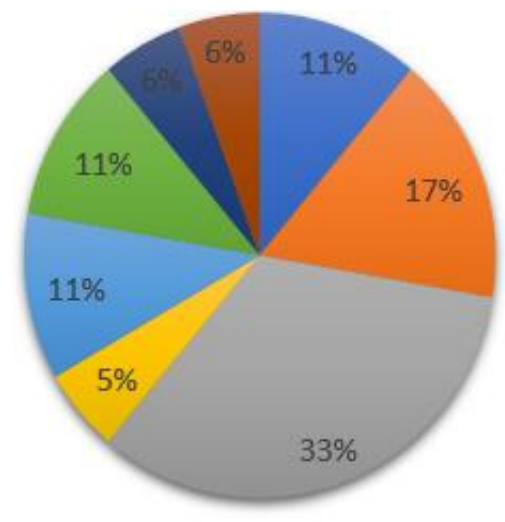

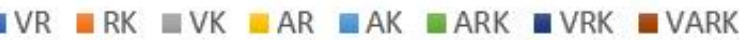

Figure 3. Percentage of respondents chosen combination of learning styles

Table 3 summarized the relationship between respondent from different courses and their learning style. A simple logistic regression was performed to define the relationship. Throughout the finding, there is no significant association between the courses and learning styles. The coefficient estimated was negative, and the variable of courses is not significant to the model ( $p>0.05)$. Table 4 tabulates the statistical analysis between learning styles and academic performance based. Notably, there was no significant relationship between learning styles and academic performance respondents using Pearson's Chi-square test $(p>0.05)$. Hence, both were independent of one another.

Table 3. The relationship between learning styles and different courses in KPJUC

\begin{tabular}{cccccc}
\hline Courses & Regression coefficient (b) & Wald statistic & EXP(B) & $95 \%$ CI & p-value \\
\hline BOT & 0.0 & .303 & 0.000 & $0.000-0.000$ & .998 \\
BON & -19.853 & .000 & .0804 & $0.225-2.869$ & 1.000 \\
BPT & -0.219 & .113 & 0.742 & $0.209-2.635$ & .736 \\
BPS & -0.299 & .213 & 0.643 & $0.066-6.250$ & .644 \\
BPH & -0.442 & .145 & 0.000 & $0.000-0.000$ & .703 \\
BMI & -19.853 & .000 & 0.259 & $0.000-0.000$ & .998 \\
\hline
\end{tabular}


Table 4. The association between learning styles and academic performance.

\begin{tabular}{cccc}
\hline Learning styles & High academic achievement $\mathrm{n}(\%)$ & Low academic achievement $\mathrm{n}(\%)$ & $\mathrm{p}$-value \\
\hline Unimodal & $45(37.8)$ & $74(62.2)$ & $0.590^{\mathrm{a}}$ \\
Multimodal & $8(44.4)$ & $10(55.6)$ & \\
\hline
\end{tabular}

\section{DISCUSSION}

This study evaluated the learning styles among healthcare students through the cross-sectional survey study. The survey extracts the features of the respondents into two parts, which first is demographic data and then, their preferred learning styles. Respondents were from various courses where 23 male and 114 females' students participate in the study. Based on the analysis of the academic achievement among healthcare students, $61 \%$ of respondents in the group of low academic achievement and another $39 \%$ of respondents fall in the group of high academic achievement.

Most of the respondents prefer unimodal mode as their preferred learning styles compared to multimodal learning styles. The dominant learning styles they prefer were visual. It can see from Table 2 , with a percentage of $32.1 \%$, and the second preference was reading/writing $(25.5 \%)$. It was realized that both males and females prefer unimodal than multimodal learning styles. These results are like the study conducted by Veena among undergraduate students of pure science and applied sciences courses [9]. In this study, $80 \%$ of the students preferred unimodal learning styles as their learning techniques. One study found that the second year of dental students preferred using unimodal as their learning methods. Besides, most dental students preferred visual (V) as their learning method than the other three modes [10]. This could be due to the difference between conventional and traditional didactic lectures in their college [11].

Another study in Malaysia found that medical students in their university preferences learning styles were unimodal [12]. In addition, Kumar, et al. state that $51.4 \%$ preferred unimodal study among engineering students [13]. A study conducted by Zain, et al. found that all students were unimodal learners for the four faculty in the private university in Selangor [14]. The highest number was kinestatitc (30.3\%) followed by visual learners (28.4\%), interestingly the visual learners most of the time are females' students similar to our study. Besides, Md Zain et al also mentioned students in the social science cluster are more preferred an Aural (A) learning style as compared to the students in pure science cluster which are more preferred Read/Write (R) learning style.

However, there was also another study found that more than $60 \%$ of medical students in Saudi Arabian preferred to learn using more than one mode, which known as multimodal learning styles [2]. In contrast with our study and Md Zain, et al. study that showed unimodal is the most preferred method of learning in Malyasia compared to the multimodal [14, 15]. This may be due to the geography, culture, and technology used in institutions that influences student preferences.

Most of the students preferred visual learning styles as and found to be in line with our findings. Based on the results from Table 3, there was no association between learning styles among healthcare courses. Furthermore, there was no association between learning styles and academic performance among undergraduate healthcare students. Another relevant factor are due to students' lack of English competency, and therefore, the students prefer to learn on their methods [16]. A similar finding can be found on a conducted survey in medical school in Pakistan where the undergraduate students in various medical colleges in Pakistan were not taught in their learning preferences styles [17].

Another study indicated that the factor affected academic performance was communication and the proper guidance from the lecturer [18]. Besides, facilities provided in the institution such as laboratory, computer lab, and library proper used by the students, significantly affected their performance [19, 20]. For example, healthcare students they learned from various method especially observed and hand on during the practical session. They need to carry out a procedure by visualize and understand the protocols before applying in the real-world situation. Hence, the information and knowledge able to store in their long-term memory for future recall. Most of the outcome of the study demonstrates the positive association between academic performance with the students who preferred to study alone. There was slightly different in the respondent's preferred learning styles. Some of the respondent prefer reading and writing as the dominant learning styles then followed by the visual. This might due to the environment of study, where some of the courses require one to remember all chemical names, human anatomy and specific skill related to the injuries. Hence, the reading and writing part become the dominant learning styles for the most of respondents. Meanwhile, the reason of the respondents prefers visual than kinaesthetic was due to their working culture. For example, become a pharmacist student need to practice how to dispense the medication to the patient correctly. Therefore, some of the dominant learning styles needed to be accepted based on their professionalism. Overall, there were no specific learning styles where the respondents needed to follow. Learning styles is based on how the individual learn and gain information. The different in learning style preference could be due to individually unique ways of educational activity depending on its own cluster

Evaluation of healthcare science student learning styles based VARK analysis technique (Izdihar Kamal) 
[14]. Therefore, each respondent might have different learning styles from each other. Notably this study could be linked to the "David Kolb 's Experiential Learning Theory" where the knowledge is gained through integrating the experience from the practical and clinical connection at the hospital during posting [7].

Another study from Mangold et al. reinforce the need to consider the variations in nurses' learning styles and tailor curriculum to reinforce these preferences. Whereas limited knowledge is available in the literature, this study supports learning activities that integrate visual and sensing learning mediums [21]. Like the findings of the McCrow, et al. studies, the results showed that sensing and visual learning styles were favoured among those studied [22].

On the other hand, another study reported the association between learning styles and academic achievement in medical education has been extensively researched but remains inconclusive. Most studies point out that there is no impact on academic performance of learning styles [23-26]. It is consistant with our study finding, however Hur \& Kim have shown that Korean medical students with a reflective learning style of choice have substantially enhanced engagement, problem-solving, quiz and teamwork [27-29]. In addition, there is scientific evidence that students with intuitive learning preferences perform substantially better than students with sensory preferences in basic science, general pathology and clinical pathology [30, 31].

This limitation of the study includes a small sample size, and all respondents were from the onesingle institution. The lack of number of respondents can directly affect the results. Since the method of collect data is through purposive and convenience sampling from a single institution was chosen, there is high chances of biased in the finding. Additionally, the population of female is more than male and may affect the insignificant of the results.

\section{CONCLUSION}

There was no clear relationship between the learning styles of respondents and their academic achievement. Most of the respondents prefer unimodal than multimodal and their preference style are visual. Hence, students need to aware about their learning technique to achieve better results. Concerning the preferred teaching technique, lecturers need to adapt to the teaching method which suitable based on the student's preference, especially among healthcare student-some of the dominant learning styles needed to be accepted based on their future profession.

\section{ACKNOWLEDGEMENTS}

The authors wish to acknowledge support from Research Management Center of KPJ University College and Geran Putra Siswazah number 9683700.

\section{REFERENCES}

[1] B. Heffler, "Individual Learning Style and the Learning Style Inventory," Educational Studies, vol. 27, no. 3, pp. 307-316, 2001.

[2] A. Nuzhat, R. O. Salem, M. S. A. Quadri, and N. Al-Hamdan, "Learning style preferences of medical students: a single-institute experience from Saudi Arabia," International Journal of Medical Education, vol. 2, pp. 70-73, Aug. 2011.

[3] N. Omar, M. M. Mohamad, and A. N. Paimin, "Dimension of Learning Styles and Students' Academic Achievement," Procedia-Social and Behavioral Sciences, vol. 204, pp. 172-182, Aug. 2015.

[4] S. Joy and D. A. Kolb, "Are there cultural differences in learning style?" International Journal of Intercultural Relations, vol. 33, no. 1, pp. 69-85, 2009.

[5] S. B. J. Neha S Kulkarni, P.A. Patil, "Learning Styles Preferences of First Year Medical Students of J N Medical College Belgaum: A Single Institute Experience in Karnataka, India," National Journal of Integrated Research in Medicine, vol. 6, no. 3, pp. 80-83, 2015.

[6] E. Sadler-Smith, "The relationship between learning style and cognitive style," Personality and Individual Differences, vol. 30, no. 4, pp. 609-616, 2001.

[7] D. A. Kolb, "Experiential Learning: Experience as the Source of Learning and Development," Prentice Hall, Inc., 1984.

[8] N. D. Fleming, "I'm different; not dumb. Modes of presentation (VARK) in the tertiary classroom," in Research and Development in Higher Education, Proceedings of the Annual Conference of the Higher Education and Research Development Society of Australasia, 1995.

[9] N. Veena and S. Shastri, "Learning Preferences among Students," IOSR Journal of Humanities and Social Science, vol. 15 , no. 6 , pp. 26-32, 2013

[10] R. J. Murphy, S. A. Gray, S. R. Straja, M. C. Bogert, "Student Learning Preferences and Teaching Implications," Journal of Dental Education, vol. 68, no. 8, pp. 859-866, 2004. 
[11] K. Pentapati, R. Saran, and S. Kumar, "Assessment of learning preferences among dental students using Visual, Aural, Read-Write, Kinesthetic questionnaire: An institutional experience," Journal of Dental Research and Review, vol. 2, no. 1, pp. 10-12, 2015.

[12] S.-C. Liew, J. Sidhu, and A. Barua, "The relationship between learning preferences (styles and approaches) and learning outcomes among pre-clinical undergraduate medical students," BMC Medical Education, vol. 15, no. 1, p. 44, 2015.

[13] L. R. Kumar, K. Voralu, S. P. Pani, and K. R. Sethuraman, "Predominant learning styles adopted by AIMST University students in Malaysia," South East Asian Journal of Medical Education, vol. 3, no. 1, pp. 37-46, 2009.

[14] Md. Zain, N. A., Tamsir, F., Ibrahim, N. A., Poniran, H., and Mohd Ghazali, A. S., "VARK Learning Styles Towards Academic Performance Among Students of Private University in Selangor," International Journal of Modern Trends in Social Sciences, vol. 2, no. 10, pp. 01-12. 2019

[15] M. Sankey, D. Birch, and M. Gardiner, "The impact of multiple representations of content using multimedia on learning outcomes across learning styles and modal preferences," International Journal of Education and Development using Information and Communication Technology, vol. 7, no. 3, pp. 18- 35.2012

[16] S. M. C. B. Karalliyadda, "Learning Style and Academic Performance of First Year Agricultural Undergraduates: A Case in Rajarata University of Sri Lanka," Journal of Agricultural Sciences-Sri Lanka, vol. 12, no. 1, pp. 34-42, 2017.

[17] M. Chaudhary, et al., "Association of academic performance with learning style preference of medical students: Multi-center study from Pakistan," Journal of Contemporary Medical Education, vol. 3, no. 3, pp. 110-113, 2015.

[18] S. D. Ghazvini and M. Khajehpour, "Gender differences in factors affecting academic performance of high school students," in Procedia - Social and Behavioral Sciences, 2011, vol. 15, pp. 1040-1045.

[19] Mushtaq, Irfan, and Shabana Nawaz Khan, "Factors Affecting Students' Academic Performance," Global Journal of Management and Business Research, vol. 12, no. 9, pp. 17-22, 2012.

[20] Ali, Norhidayah, Kamaruzaman Jusoff, Syukriah Ali, Najah Mokhtar, and Azni Syafena Andin Salamat, "The Factors Influencing Students' Performance at Universiti Teknologi MARA Kedah, Malaysia,” Management Science and Engineering, vol. 3, no. 4, pp. 81-90, 2009

[21] K. L. Mangold, et al., "Learning Style Preferences of Practicing Nurses," Journal for Nurses in Professional Development, vol. 34, no. 4, pp. 212-218.2018

[22] J. McCrow, A. Yevchak, and P. Lewis, "A prospective cohort study examining the preferred learning styles of acute care registered nurses," Nurse Education in Practice, vol. 14, no. 2, pp. 170-175. 2014

[23] Hernández-Torrano, D., S. Ali, and C. Chan, "First year medical students' learning style preferences and their correlation with performance in different subjects within the medical course," BMC Medical Education, vol. 17, no. 1, p. 131. 2017

[24] S. Tariq, et al., "Association between academic learning strategies and annual examination results among medical students of King Edward Medical University," Annals of King Edward Medical University, vol. 22, no. 2, pp. 124$134,2016$.

[25] T. H. Almigbal, "Relationship between the learning style preferences of medical students and academic achievement," Saudi Medical Journal, vol. 36, no. 3, pp. 349-355. 2015

[26] R. P. Urval, A. Kamath, S. Ullal, A. K. Shenoy, N. Shenoy, L. A. Udupa, "Assessment of learning styles of undergraduate medical students using the VARK questionnaire and the influence of sex and academic performance," Advances in Physiology Education, vol. 38, no. 3, pp. 216-220, 2014

[27] Y. Hur and S. Kim, "Different outcomes of active and reflective students in problem-based learning," Medical Teacher, vol. 29, no. 1, pp. 18-21, 2007

[28] Sutcliffe L., "An investigation into whether nurses change their learning style according to subject area studied," Journal of Advanced Nursing, vol. 18, no. 4, pp. 647-665, 1993.

[29] C. Kreber, "The relationship between self-directed learning, critical thinking, and psychological type and some implications for teaching in higher education," Studies in Higher Education, vol. 23, no. 1, pp. 71-78, 1998

[30] D. F. Wood, "ABC of learning and teaching in medicine: Problem based learning," BMJ, vol. 326, no. 7384, pp. 328-330, 2003.

[31] A. A. Alghasham, "Effect of students' learning styles on classroom performance in problem-based learning," Medical Teacher, vol. 34, no. 1, pp. S14-S19, 2012. 